\title{
ATENÇÃO A SAÚDE DO HOMEM NA UNIDADE DE SAÚDE DA FAMÍLIA SALOBRINHO II
}

\author{
Meire Nubia Santos de Santana \\ Universidade Federal Rural do Rio de Janeiro \\ meirenubia@yahoo.com.br \\ Eliana Santos Goldman Pinto \\ Escola Estadual de Saúde Pública/Bahia \\ eliana.sgp@gmail.com \\ Regina Lúcia de Almeida Lino Vieira \\ Universidade Estadual de Santa Cruz \\ reginalinovieira@gmail.com \\ Geferson André da Silva Costa \\ andre-scosta@hotmail.com \\ Leonam Sodré Santana \\ Universidade do Estado da Bahia \\ djesleonam@hotmail.com \\ Melchisedeck Lemos Nascimento \\ melchisedeckl@yahoo.com.br \\ Priscila Sousa Silva \\ priscilla14@hotmail.com \\ Tainan Lopes Seara \\ thaii_seara@hotmail.com
}

\begin{abstract}
Resumo
A Atenção à Saúde do Homem constitui um foco atual de discussão no Sistema Único de Saúde. Compreende-se que por meio de um atendimento integral à saúde desta população, seja possível reduzir o número de agravos e problemas de saúde em faixas etárias mais elevadas e entre os mais jovens, além de proporcionar melhor qualidade de vida para o homem e sua família. Entretanto, admite-se que a adesão da população masculina aos serviços de saúde seja, comparativamente, inferior à observada em parcelas de outros grupos populacionais e muito aquém das reais necessidades que os homens demandam. Esse trabalho constitui-se de uma pesquisa qualitativa realizada no bairro do Salobrinho na população adscrita à Unidade de Saúde da Família Salobrinho II, no município de Ilhéus, no período de janeiro a março de 2013. Foram coletadas informações relativas ao ponto de vista quanto ao adoecimento, qualidade do serviço, fatores que favorecem a adesão, dentre outros, para permitir uma posterior adaptação do serviço às expectativas do homem quanto aos serviços de saúde prestados. Espera-se que esta reflexão seja transformada em melhorias para atendimento dos homens que constituem a clientela do Salobrinho, ao mesmo tempo em que torne possível compartilhar experiências no tocante ao serviço de saúde prestado à população masculina e às comunidades carentes dos bairrosperiféricos.
\end{abstract}

Palavras-Chave: Saúde do Homem. Saúde Pública. Atenção Básica. 


\title{
ATTENTION TO THE HEALTH OF THE MAN IN THE HEALTH UNIT OF THE FAMILY SALOBRINHO II
}

\begin{abstract}
Attention to Men's Health is a current focus of discussion in the Unified Health System. It is understood that through a comprehensive health care of this population it is possible to reduce the number of injuries and health problems in older age groups and among the youngest,furthermore to provide better health conditions for the man and his family. However it is accepted that adherence to health services of the male population is comparatively lower than that observed in other population plots and far short of real needs that men demand. The following work consists of a qualitative research conducted in Salobrinho neighborhood in the population enrolled in the Family Health Unit Salobrinho II in the city of Ilheus, between January-March of 2013. It has been collected information related to the illness quality of service, factors that favor membership, among others, to enable further adaptation of the front service to the expectations of men as to health services. It is hoped that this reflection is transformed into improvements to men's service who compose the Salobrinho'scostumer bases, while it is possible to share experiences regarding the health service to the male population and poor communities andsuburbs.
\end{abstract}

Keywords: Men's Health. Public Health. Primary Care.

\section{ATENCIÓN LA SALUD DEL HOMBRE EN LA UNIDAD DE SALUD DE LA FAMILIA SALOBRINHO II}

\begin{abstract}
Resumen
La atención a la salud del hombre constituye un foco actual de discusión en el Sistema Único de Salud. Se entiende que por medio de una atención integral a la salud de esta población, sea posible reducir el número de agravios y problemas de salud en franjas etarias más elevadas y, entre los más jóvenes, además de proporcionar una mejor calidad de vida para el hombre y su familia. Sin embargo, se admite que la adhesión de la población masculina a los servicios de salud sea, comparativamente, inferior a la observada en parcelas de otros grupos poblacionales y muy por debajo de las reales necesidades que los hombres demandan. Este trabajo se constituye de una investigación cualitativa realizada en el barrio del Salobrinho en la población adscrita a la Unidad de Salud de la Familia Salobrinho II, en el municipio de Ilhéus, en el período de enero a marzo de 2013. Se recogieron informaciones relativas al punto de vista en cuanto al la salud, la calidad del servicio, factores que favorecen la adhesión, entre otros, para permitir una posterior adaptación del servicio a las expectativas del hombre en cuanto a los servicios de salud prestados. Se espera que esta reflexión sea transformada en mejoras para la atención de los hombres que constituyen la clientela del Salobrinho, a la vez que haga posible compartir experiencias en lo que se refiere al servicio de salud prestado a la población masculina ya las comunidades carentes de los barrios periféricos.
\end{abstract}

Palabras clave: Salud del Hombre. Salud Pública. Atención Básica. 


\section{INTRODUÇÃO}

O Programa Saúde da Família (PSF), atualmente denominado Estratégia Saúde da Família (ESF), foi concebida pelo Ministério de Saúde em 1994, com o propósito de substituição do Modelo de Atenção médico-assistencialista, centrado na visão biologicista do processo saúde-doença e na priorização das ações curativas.

Segundo GARUZI et al. (2014, p.144-145),

O Programa Saúde da Família, criado e implantado em 1994, é uma importante estratégia para reorganizar as práticas na APS $^{1}$ e reorientar o sistema de saúde brasileiro, por meio do sistema de referência e contrarreferência. O Programa articula os demais níveis de complexidade de atenção com a APS, garantindo, assim, a integralidade das ações e a continuidade do cuidado.

Assim, com a implantação da Estratégia Saúde da Família (ESF), o Ministério da Saúde objetivou organizar a rede de atenção básica, ofertando serviços que possam dar resolutividade aos problemas de saúde da população brasileira na perspectiva de garantir os princípios doutrinários e organizativos do Sistema Único de Saúde, através dos diversos programas e intervenções implantados no âmbito da Unidade de Saúde da Família.

A execução das ações de saúde desses programas vem desempenhando um grande impacto no atendimento da população brasileira, resultando em mudanças significativas no perfil epidemiológico e alterações nos indicadores de saúde. Entretanto, comprovadamente a ESF ainda evidencia falhas no que tange ao cuidado longitudinal e contínuo com a população masculina, tornando o acesso e as ações de promoção e prevenção limitados a intervenções pontuais. MOURA et al. (2014), enfatizam que a busca dos homens por atendimento nos serviços de saúde está concentrada nos agravos e nas doenças, em situações que exigem especialidades ou são de extrema urgência, diferindo do comportamento das mulheres em relação ao uso de tais serviços.

Em consonância com esse fator, observa-se, também, que o atendimento da família pela ESF é focado no acompanhamento de grupos prioritários, com ênfase em mulheres e crianças, deixando visível uma lacuna no atendimento à população masculina. Sabe-se que este grupo populacional sofre de adoecimentos próprios que necessitam ser contemplados por políticas de saúde específicas. “Tradicionalmente, os

${ }^{1}$ Atenção Primária em Saúde. 
homens não têm suas especificidades reconhecidas e não fazem parte das populações usualmente mais assistidas nos serviços de atenção básica à saúde" (MOURA et al., 2014, p.430).

O Ministério da Saúde idealizou, para tal, a política de Assistência à Saúde do Homem, com o intuito de corrigir esta distorção e promover atenção à saúde para a população masculina, através da implantação de campanhas, realocação de recursos e treinamento de profissionais de saúde, dentre outras medidas para enfrentamento do problema.

Implantada através da Portaria GM/MS n 1944, em 27 de agosto de 2009, a Política Nacional de Atenção Integral à Saúde do Homem (PNAISH) busca a resolutividade das demandas de saúde apresentadas pelo homem na sua pluralidade e considerando as mais variadas condições de existência (CHAKORA, 2014). Portanto, as medidas contemplam a necessidade de reduzir o impacto de fatores culturais que limitam a procura por serviços de saúde a situações extremas ou a estágios avançados de adoecimento e valoriza a participação masculina como elo importante para a sociedade.

Levando em consideração as Unidades de Saúde como lócus das práticas que reorientam o fazer em saúde para garantir um cuidado integral aos homens, Hardman et al. (2013, p. 97) colocam que:

\begin{abstract}
A Unidade Básica de Saúde é o melhor local para educar e estimular a comunidade masculina a adotar hábitos preventivos. A prevenção é veiculada a uma ação orientada, cuja finalidade é não permitir que o indivíduo adoeça, e assim, possa ter melhor qualidade de vida. E para a prevenção e promoção da saúde da população (...) E que a saúde masculina, por ser pouco debatida e abordada se comparada à saúde feminina, precisa ser objeto de investigações e reconhecimento social.
\end{abstract}

Nessa perspectiva é interessante considerar as particularidades do processo do adoecer do homem, sua exposição a fatores de risco, assim como sua inserção no ambiente familiar. Deste modo, as Unidades de Saúde da Família (USF) devem preparar-se para novas rotinas de prestação de serviços que contemplem as orientações voltadas para a atenção à saúde do homem.

Na Unidade de Saúde da Família do Salobrinho II, localizada no município de Ilhéus-BA, onde se desenvolvem atividades do Programa de Educação pelo Trabalho para à Saúde, observou-se que a procura pelos serviços de saúde entre homens é, em quase sua totalidade, representada pelo atendimento de homens hipertensos e diabéticos. É provável que existam fatores que limitem a procura ou o acesso desta população aos 
serviços de saúde, mas é preciso observar quais condicionantes são estes.

Essa e outras questões instigadoras serviram de estímulo para a realização desse estudo, pois além de possibilitar a melhor adequação da USF à realidade da população adscrita, através dos dados obtidos, também poderá trazer à luz novos desafios e caminhos a serem (re)pensados por outras equipes de saúde.

Baseando-se nos pressupostos supracitados, tem-se como objetivo geral: Analisar os principais entraves da procura e do acesso do homem à Unidade de Saúde da Família Salobrinho II; e objetivos específicos: (1) Identificar como o homem, residente no Salobrinho, avalia o processo de saúde-doença ao qual está exposto; (2) Verificar quais os principais entraves na procura por serviços de saúde, e (3) Conhecer as impressões e expectativas do homem sobre o atendimento da Unidade de Saúde da Família Salobrinho II.

\section{METODOLOGIA}

Trata-se de um estudo exploratório descritivo de natureza qualitativa. Segundo Gonçalves (2014, p.168), a “[...] pesquisa exploratória visa à descoberta, ao achado, à elucidação de fenômenos ou à explicação daqueles que não eram aceitos, apesar de evidentes". Portanto, permite ao pesquisador conhecer ideias, esclarecer conceitos e adquirir familiaridade com o objeto de estudo.

Utilizou como instrumento de coleta de dados um questionário semiestruturado para a realização das entrevistas com os moradores do Salobrinho, moradores estes, que satisfizessem as condições previamente estabelecidas, tais como: ser do sexo masculino, residente do Salobrinho na zona adscrita à Unidade de Saúde da Família Salobrinho II, ter mais de 19 anos de idade, concordar com a sua participação no estudo por meio de termo de consentimento livre e esclarecido, aceitar ter sua entrevista gravada em áudio e permitir a publicação de suas respostas, sem identificação nominal.

As entrevistas ocorreram no período de janeiro a março de 2013 e foram conduzidas por meio de diálogos, gravadas, posteriormente transcritas e, por último, analisadas. Convém ressaltar que os quatro entrevistadores foram divididos por microáreas de abrangência da Unidade de Saúde da Família Salobrinho II. No momento da pesquisa, três áreas eram assistidas por seus respectivos agentes comunitários, e uma estava descoberta, ou seja, sem agente de saúde alocado no espaço territorial. Desta forma, os dados colhidos não constituem uma amostra de todo abrangente. Verificaram- 
se diferenças sensíveis entre os territórios da pesquisa, seja na faixa etária dos pacientes ouvidos, seja nas condições socioeconômicas, assim como na disponibilidade em participar do estudo e até quanto ao teor das respostas fornecidas. Estas discrepâncias serão tratadas de forma particular na avaliação das informações colhidas.

Por motivos práticos, a discussão será estruturada em condicionantes de saúde e doença sob o ponto de vista do morador do Salobrinho, sua relação com os serviços de saúde de forma geral e suas expectativas e avaliações quanto ao serviço de saúde no Salobrinho, e tudo isto será analisado com respaldo da literatura vigente sobre a temática trabalhada e suas áreasafins.

\section{RESULTADOS E DISCUSSÃO}

\section{A visão masculina no Salobrinho sobre o processo saúde-doença}

Uma das primeiras etapas para compreender a saúde do homem é entender de que forma ele se considera sadio ou o que significa estar doente, e dessa forma buscar conhecer a percepção e a subjetividade produzida pelos atores envolvidos na pesquisa.

Sabe-se que, como afirmam Câmara et al. (2012 p. 42),

[...] apesar de todos os conceitos estabelecidos sobre saúde e doença, sabe -se que eles, ao longo dos anos, têm sido compreendidos ou enfrentados de acordo com as diversas formas de existir das sociedades, expressas nas diferentes culturas e formas de organização. Eles dependem do entendimento que se tem do ser e de sua relação com o meio em que está inserido. Esse entendimento varia de acordo com a cultura de cada lugar e o momento histórico. Por tudo isso, a conceituação de saúde se faz tão difícil de ser fixada, uma vez que está condicionada ao momento histórico e às condições concretas e peculiares de existência.

Nessa perspectiva, conhecer quais os elementos psicossociais que motivam o homem a buscar os serviços de saúde é essencial para entender a visão masculina sobre essa temática. Para isto, a população do estudo foi estimulada a responder e conversar sobre tópicos diversos que abrangiam a sua relação com a saúde e com o adoecimento.

Quando questionados quanto aos aspectos mais importantes de sua vida, como família, amigos, trabalho, diversão e renda (dinheiro), a maioria dos entrevistados afirmou que a saúde era o mais importante, no momento, em suas vidas. A resposta a esta questão obviamente apresentou variações importantes. Entre os pesquisados acima de 65 anos de idade ou os que recebiam benefícios, esta foi praticamente a única resposta obtida. Nos pesquisados em faixas etárias menores, trabalho, saúde e família tornaram-se respostas mais prevalentes. 
Vale destacar que os entrevistadores se identificaram como estudantes da área de saúde, e como esta era a primeira questão a ser respondida, é possível que muitos dos atores sociais tenham sido induzidos a ressaltar a importância da saúde em sua vida diante dos mesmos. Entretanto, quando orientados a justificar porque a saúde era tão importante em sua vida, os sujeitos da pesquisa na faixa etária acima de 65 anos argumentavam a fragilidade de sua condição física e a redução da relevância de outros aspectos sociais como importantes em sua rotina em detrimento da saúde.

Escolher a saúde como o aspecto mais importante, não necessariamente indica que esta seja, de fato, a prioridade no dia a dia dos entrevistados. Contudo, a escolha da saúde como prioridade, mesmo que não reflita a realidade, indica uma busca por adquirir uma saúde ideal por parte desses sujeitos. Ou seja, sugere que, no imaginário dessas pessoas, o cuidado com a saúde é uma necessidade fundamental, mesmo que, na prática, elas não tenham acesso ao atendimento básico necessário, na sua percepção, para garantir a qualidade de vida desejada.

Quanto aos demais, entrevistados, tanto da faixa etária mais jovem quanto da acima de 65 anos que não referiram saúde como prioridade, as respostas mais frequentes foram: religião, renda (dinheiro) e o convívio social. Essas respostas induzem à análise da posição de provedor ocupada pelo homem, que ao longo do tempo foi sendo culturalmente enraizada na sociedade. Em seu estudo sobre os fatores impeditivos de procura pelo serviço por parte da população masculina, Levorato et al. (2014) apontam que uma das principais preocupações desse público, principalmente os de baixa escolaridade, está voltada mais para o sustento da família que para os cuidados com sua própria saúde. Corroborando com esse pensamento, Ribeiro, Gomes e Moreira (2017) discorrem sobre as representações que estão vinculadas ao gênero, reduzindo a percepção de saúde integral dos sujeitos:

\footnotetext{
As representações culturais de força e vigor, associadas ao trabalho, e a centralidade da sexualidade como conquista, contrastam com as noções construídas sobre o feminino, que se inscreve no campo da reprodução, do controle da sexualidade e da disciplina e cuidado. Essas reduções não contribuem para uma perspectiva de integralidade em saúde (RIBEIRO; GOMES; MOREIRA, 2017, p.44).
}

Outra percepção da saúde nos achados da pesquisa de Câmara et al. (2012, p. 45) foi relacionada à qualidade de vida:

[(...)] o conceito de saúde se relaciona intimamente à qualidade de vida, amplia a concepção de saúde apenas como ausência de doença e representa um grande avanço, porque manifesta o desconforto dos profissionais sobre o 
reducionismo biomédico.

Ainda na análise das entrevistas, Câmara et al (2012, p.45) observaram que

[...] o processo saúde-doença, ainda hoje, está intimamente relacionado ao processo fisiopatológico em si, devido à frequente presença da doença em relação com a manifestação de mal-estar físico. Além disso, a análise conjunta dos dois conceitos, saúde-doença, permite afirmar que, embora o conceito ampliado da OMS para saúde seja bastante divulgado e reproduzido nas falas, ele não é de todo compreendido, pois os profissionais da saúde entrevistados revelaram, em suas respostas, que não conseguem perceber a saúde em toda a sua dimensão.

Portanto, o processo saúde é um fenômeno complexo e a percepção das pessoas sobre o tema é variado. Pode-se ter diversos tipos de entendimento e ser passível de modificações. Enfim, a conceituação depende das vivências e da visão de mundo de cada ator social.

Embora alguns estudos revelem a priorização dos homens pela família e o seu sustento, é curioso que boa parte dos entrevistados não considerou a família como prioridade, havendo certa discordância entre a literatura e os resultados obtidos. A condição de morar sozinho, ou não conviver com família nuclear podem ter motivado essa opção.

É provável que muitos núcleos familiares da população do Salobrinho não estejam estruturados dentro desses padrões tradicionais e que o cuidado da saúde desses homens, por parte de sua família, seja incipiente. Em um núcleo familiar, onde os indivíduos têm mais cuidado uns com os outros, espera-se um reflexo positivo na saúde dessas pessoas. A família, para esses homens, não parece exercer um papel decisivo no processo saúde e doença.

A fala abaixo, de um dos entrevistados, caracteriza essa ideia:

"O que é mais importante para mim hoje é a saúde, o dinheiro e a fé em Deus." (Ent 4)

\section{A percepção subjetiva de vida saudável para o homem do Salobrinho}

A preocupação com a qualidade de vida $(\mathrm{QV})$ do ser humano tem sido alvo de diversos debates na atualidade, e constitui-se em um compromisso dos indivíduos na busca contínua de uma vida saudável, compreendendo como um bem-estar indissociável das condições do modo de viver, como: saúde, moradia, educação, lazer, transporte, liberdade, trabalho, autoestima, entre outras. 
O conceito de qualidade de vida, para Paschoal (2006), surge a partir da subjetividade humana. Esta definição remete ao entendimento de que qualidade de vida é algo muito singular para cada ser humano, baseado em sua vida cotidiana, que se apresenta, conforme o contexto social, histórico, cultural, divergindo o significado de vida saudável de pessoa para pessoa na dimensão espaço tempo.

Corroborando com esse pensamento, Neves et al. (2014, p. 554) afirmam que "QV é um construto complexo e multidimensional que requer abordagem de diferentes ângulos, levando-se em consideração aspectos subjetivos e objetivos e dimensões positivas e negativas.”. A diversidade de respostas obtidas nesse estudo sobre a temática vida saudável reflete o pensamento dos autores citados anteriormente. Destacam-se, a seguir, fragmentos das falas dos entrevistados, quando questionados eles se consideravam saudáveis.

ENTREVISTADO 1: Sim, graças a Deus. Porque eu não ando fumando, não ando bebendo, não ando em lugar nenhum. Só dentro de minha casa. Sou feliz demais. (Risos)

ENTREVISTADO 2: Não sei o que é nem saudável. Não sei o que significa. Sei não. ENTREVISTADO 3: Eu me considero, porque aos trancos e barranco a gente vai levando a vida, porque quem ta vivendo no bom é quem tem dinheiro, é o rico. Esse aí vive numa boa, não tem mosquito. Agora o pobre, nem todo dia, se ele adoecer, nem todo dia tem dinheiro para comprar um comprimido, nem nada. A pessoa ser saudável é quando a pessoa não sente nada. a pessoa ser saudável, sadiamesmo.

ENTREVISTADO 4: Eu me considero porque sou uma pessoa sem preocupação, assim tranquilo.

ENTREVISTADO 5: Com certeza. Porque eu sou uma pessoa sadia. Me dou com todo mundo. Todo mundo eu faço amizade. Tenho várias amizades. Sempre só gosto de construir amizade. Nunca gostei de inimizade. Eu também acho que sou saudável assim.

ENTREVISTADO 6: Sim, me considero. Por que? Assim minha maneira de ser, entendeu? Sou disposto, não tenho preguiça.

Por meio desta amostra, percebe-se que os entrevistados possuem visões díspares sobre o que contribui para que sejam saudáveis, ou não. Para alguns, a ausência 
de preocupações e o bom convívio social são os principais elementos que justificam a sua saúde. Para outros, considerar-se saudável, ou não, é algo difícil de expressar. Poucos se definiram como saudáveis pela negação de estados patológicos.

A vida saudável parece estar mais relacionada à preservação de elemento positivos por essa população. Este tipo de resposta demonstra uma visão otimista da vida. Contudo, ao se definirem como saudáveis, muitos homens desconsideram elementos biológicos importantes do envelhecimento, justificando desta forma, a falta de necessidade dos serviços de saúde.

\title{
Concepção do adoecimento para a população masculina do Salobrinho
}

O processo do adoecimento tem sido alvo de debates e produção de diversos autores. Para Sontag (1984, p.4)

\begin{abstract}
A doença é o lado sombrio da vida, uma espécie de cidadania mais onerosa. Todas as pessoas vivas têm dupla cidadania, uma no reino da saúde e outra no reino da doença. Embora todos prefiram usar somente o bom passaporte, mais cedo ou mais tarde cada um de nós será obrigado, pelo menos por um curto período, a identificar-se como cidadão do outro país.
\end{abstract}

Esse tema foi explorado e explicado desde os tempos remotos; o adoecer foi concebido como resultante de transgressões de natureza individual e coletiva para reatar o enlace com as divindades. No modelo holístico, a saúde era entendida como o equilíbrio entre os elementos e humores que compõem o organismo humano. $\mathrm{O}$ desequilíbrio desses elementos permitiria o aparecimento da doença. Já no paradigma biomédico, a doença é definida como desajuste ou falha nos mecanismos de adaptação do organismo, um processo que conduz a uma perturbação da estrutura ou da função de um órgão, de um sistema ou de todo o organismo ou de suas funções vitais. Enquanto, no arquétipo da história natural da doença, ela é considerada como o conjunto de processos interativos que cria o estímulo patológico no meio ambiente, ou em qualquer outro lugar, passando da resposta do homem ao estímulo até as alterações que levam a um defeito, invalidez, recuperação ou morte (LEAVELL; CLARK, 1976 apud ALMEIDA FILHO; ROUQUAYROL, 2013).

Para Sampaio et al. (2015, p. 103),

A definição de doença não inclui somente a experiência pessoal do problema de saúde, mas também o significado que o indivíduo confere a ela. Logo, a experiência de estar doente é única, pois os comportamentos e atitudes adotados por indivíduos em situação de doença são singulares e estão de acordo com todas as crenças e conceitos criados por sua própria vivência pessoal e pelas características da cultura que os integra. A forma como cada 
pessoa enfrenta a doença representa aspectos peculiares, englobando as formas de ser e de estar perante si mesma, o seu papel na sociedade e todas as relações que estabelece com o mundo durante a sua existência. Dessa forma, é possível dizer que a doença apresenta duas dimensões: uma física e outra experiencial. A primeira, estudada nas faculdades, é vivida cotidianamente na prática clínica pelos profissionais de saúde. A segunda, experiencial, está ligada ao paciente e a sua maneira de viver e perceber o sofrimento e a dor. Assim, toda doença é idiossincrática, pois cada um a experimenta de formas diferentes.

A concepção do que é adoecer para os moradores do Salobrinho, sujeitos dessa pesquisa, foi apreendida quando questionados sobre a identificação do problema de saúde. Surge uma variedade de respostas. Parte considerável afirmou não saber o que seria um problema de saúde. Alguns dos entrevistados optaram por uma explicação social da saúde, destacando os problemas gerenciais e administrativos como problemas de saúde.

Uma parcela não desprezível dos entrevistados associou os problemas de saúde à necessidade de cuidados médicos ou a alguma forma de incapacidade. Vejamos este exemplo de resposta do entrevistado 1 , que já fora previamente mencionado:

ENTREVISTADO 1: Ficar doente é estar nos médicos. Saúde é zelar do corpo da pessoa e da alma da pessoa também. Zelar para não criar no erro, para você não ser doente. A saúde é isso, não é um problema. O sujeito escolhe, não perder noite, não beber, não fumar.

Observa-se um discurso que reflete os hábitos de vida como um forte condicionante da saúde, mas, nota-se que, para esses sujeitos, a necessidade de cuidados médicos expressa o adoecer, enquanto a falta de procura dos serviços de saúde significa inexistência de problemas nesse campo.

Ainda foram elencados, pelos entrevistados, como problemas de saúde, as filas, a demora no atendimento, a falta de remédios, de insumos e de material humano. Alguns, também, manifestaram descrédito quanto aos serviços de saúde que receberam ou poderiam receber. Para os sujeitos desse estudo, a falta de qualidade dos serviços é considerada um fator que limita o acesso e a procura por serviços de saúde na população masculina, independente da faixa etária ou de outros aspectossociais.

Em seguida, os entrevistados eram questionados sobre o que mudariam em suas vidas para ter mais saúde. Entre os moradores com idade mais avançada, algumas 
respostas foram permeadas de sentimentos de baixa autoestima, revelando falta de perspectiva de vida, outras mais resignadas, demonstrando aceitação e acomodação com o cotidiano da vida.

ENTREVISTADO 2: Tem mais não. Tô esperando bater as botas.

ENTREVISTADO 5: Sei lá, é ...viver, sabendo viver, né? Pra não buscar a doença, porque a doença é a gente mesmo que busca. A gente acaba com o tempo permitindo que a doença chegue até a gente. Porque a gente fica é.., sei lá é...usando o corpo com... fazendo besteira, tal e com isso vai acumulando, a doença no corpo. É issoaí.

ENTREVISTADO 6: Mais saúde? Bom, mais saúde eu acho que a minha é boa né? Eu considero que a minha saúde é boa porque eu tô nessa idade, nunca fiz uma cirurgia. Vou ao médico porque é obrigação na minha idade, porque até as crianças vai, mas, pra ver como é que ta a saúde. Mas, até agora eu não tenho do que reclamar.

Quando questionados sobre os encaminhamentos frente ao adoecimento, alguns (principalmente os que estão abaixo dos 40 anos), afirmaram que a mãe era a primeira forma de auxílio buscada, independente da gravidade do problema de saúde. Outros recorriam aos tratamentos caseiros, e uma pequena parcela buscava os serviços de saúde. Isso sugere que os homens resistem a buscar ajuda de profissionais de saúde, optando pelo cuidado no núcleo familiar, cujo apoio é socialmente aceito.

\section{A forma como o homem do Salobrinho se relaciona com os serviços de saúde}

O foco desse subtema nos reporta aos serviços de saúde e aos modos relacionais dos usuários com os mesmos, uma vez que

\footnotetext{
É crescente o reconhecimento da necessidade de se considerar a perspectiva do usuário, quando se aborda a qualidade dos serviços de saúde, uma vez que, com base nessa premissa, as práticas de saúde e a própria organização do trabalho e dos serviços de saúde podem ser repensadas. Observa-se a demanda por atendimento nos serviços de saúde por meio de consultas, exames, administração de medicamentos, realização de procedimentos, bem como por ser a busca de respostas às questões socioeconômicas, às más condições de vida, à violência, à solidão, à necessidade de vínculo com um serviço ou profissional ou, ainda, o acesso a alguma tecnologia específica que possa proporcionar qualidade de vida, expressando, assim, as necessidades do usuário. Para o atendimento dessas necessidades, os serviços de saúde devem ser organizados, de modo que a atenção primária assuma o caráter de reordenação do sistema em uma rede articulada e integrada. (GOMIDE et al.,
} 
2012, p.20).

Essa temática, quando abordada nas entrevistas, foi respondida por boa parte deles afirmando que não procuram auxilio nos serviços de saúde. Uma pequena parcela, recorre rotineiramente às instâncias de atenção à saúde, e só aumenta esta frequência com o avanço da idade e a presença de comorbidade.

Em muitos discursos é nítida a relação entre estar doente e precisar "ir ao médico". O caráter preventivo nas consultas e na busca aos serviços de saúde ainda é incipiente, muitas vezes até ignorado ou negligenciado pelo homem.

Os registros transcritos a seguir revelam a relação dos homens com os serviços de saúde:

ENTREVISTADO 4 A frequência que eu vou é a doença que tiver. Se tiver com dor de dente é dor de dente. Se tiver com a barriga doendo é a barriga doendo, o corpo quebrado é o corpo quebrado, né? É isso. Com saúde eu não vou. Eu tô aqui, para que ver médico?

ENTREVISTADO 7 A última vez foi quando eu caí doente. Deixa eu ver, faz um outro tanto [gesticula para indicar muito tempo]. Nem recordo se ocorreu nada.

Nota-se que o caráter preventivo dos serviços de saúde não atinge parcela considerável dos homens. A grande maioria deles considera que nos momentos que se manifestam sintomas e sinais de doença é que se deve comparecer "ao médico". Enfim as situações de risco iminente à saúde é que justificariam a busca por serviços desaúde. Esse comportamento remete às considerações de Burille et al. (2013, p.262), baseadas em vários autores, como (CECCHETTO, 2004; GOMES et al., 2008; BRAZ, 2005):

\footnotetext{
$[(\ldots)]$ as masculinidades são construídas histórica e socio culturalmente, sendo que sua significação é um processo em constante construção e transformação na sociedade. (...) Com relação aos eixos estruturantes da masculinidade hegemônica, enfatiza-se que existe um senso comum que atribui à identidade masculina a imagem de um ser forte, capaz, protetor, decidido e corajoso. Estas atribuições estão enraizadas em muitas culturas, nas quais a educação dos meninos segue padrões de oposição entre os gêneros, uma vez que são orientados para serem provedores e protetores e também aprendem desde cedo a suportar suas dores físicas e emocionais sem chorar.
}

Vejamos também a afirmação de BURILLE et al (2013 p. 261-263): 
[...] "ser homem é..." pertencer a uma masculinidade heteronormativa, a qual configura-se como modelo hegemônico e que se sobressaí sobre os demais modelos. É cumprir com as prescrições que estão enraizadas em nossa sociedade, nem que para isso tenham que colocar em risco sua saúde. (...) relacionar a construção social da masculinidade e o processo de adoecimento torna-se relevante, uma vez que a manutenção de papéis e de características atribuídas aos homens pode influenciar na escolha de buscar ou não cuidado. Assim, ao adotar a expressão "arranhaduras da masculinidade" parte-se do pressuposto de que buscar cuidado e saúde aproximaria os homens de um espaço de representações de feminilidade, já que o cuidado normalmente é associado a práticas femininas. Tal fato precisa ser considerado, já que repercute nas questões de saúde e pode influenciar nas trajetórias masculinas em busca de cuidado, pois no modelo hegemônico de masculinidade, o qual é considerado heteronormativo, a busca por cuidado pode causar "arranhaduras na masculinidade".

A seguir, alguns depoimentos traduzem a falta de credibilidade dos homens em relação aos serviços de saúde, revelada através das queixas quanto à precariedade das referidas unidades, da baixa qualidade de atendimento e do descaso pelos profissionais de saúde e de aspectos relacionados ao financiamento e ao gerenciamento do SUS.

ENTREVISTADO 6: É porque o atendimento não é bom. Não é bom. O atendimento não é bom. Se a pessoa tem um prêmio, reclama, se não tem, é pior. Pelo SUS, o nosso país é precário mesmo. Não tem para ondecorrer.

ENTREVISTADO 7: A estrutura dai é muito precária. Aí deveria melhorar. Aí como você trabalhando lá, tivesse uma estrutura melhor, a população estaria mais satisfeita.

ENTREVISTADO 10: A maneira do hospital melhorar é ter mais atendentes. Tratar bem o paciente quando chega. Que às vezes a pessoa chega lá, fica feito um animal, o atendimento é precário. Às vezes falta médico, falta enfermeira. Fica noscorredor lá padecendo que muita gente fica. E o tratamento do pobre de maneira geral é desse jeito.

ENTREVISTADO 12: Rapaz, para melhorar falta médico. Porque é assim você vai pro médico, vamos supor, você quer um exame: aí você vai pegar um dia pra pegar ficha, aí outro dia você vai esperar uma semana ou duas para ser atendido. E depois de ser atendido você vai ficar quase um mês ou mais pra pegar esse resultado desse exame pra tornar a pegar outra ficha para esperar o médico de novo pra entregar esse resultado pro médico. E se tivesse o médico para atender você e já dar os exames pra fazer é outra coisa. Só isso pra mim quefalta. 
Alguns entrevistados apontam a precariedade da assistência como impeditivo para estabelecer uma relação com os serviços de saúde. Salientam os problemas na estrutura e no funcionamento como entrave para o acesso aos serviços de saúde e justificam o distanciamento desses.

ENTREVISTADO 12: O que mais me prejudica é enfrentar fila. É o pior para nós, principalmente para mim, porque com a saúde dessa, ficar, enfrentar uma fila, às vez. sair daqui de madrugada, de manhã cedo quando chega lá a fila já ta com mais 30,40 pessoas na frente. Ficar ali, enfrentar fila, depois, muitas vezes, naquele dia não é atendido. E novamente vir depois. Quando acontece de ser atendido, nova fila pra enfrentar. Quando chega o ponto de a gente ser atendido já não tem nem mais graça, porque pelo tempo que a gente sofre em fila. E isso não é só na saúde, mas como a gente ta tratando de saúde, eu estou me referindo à saúde, o mau atendimento, com este problema de fila, principalmente a pessoa idosa.

ENTREVISTADO 13: O que mais dificulta é o dinheiro. Porque tando com o dinheiro a gente vai ao médico e resolve o problema, né? Vai logo pra frente, ta precisando do remédio, compra,né ? E não tendo dinheiro eu não possofazer.

ENTREVISTADO 14: A dificuldade é .... É emprego, né ? Que não tem. E tem hora que precisa de um emprego pra poder correr atrás dos médicos, que nós não temos emprego. Além do emprego, tem mais alguma coisa que dificulta? Rapaz, não. Pra mim, não.

ENTREVISTADO 10: O atendimento. O sofrimento que a pessoa fica lá esperando ser atendido. O que mais dificulta é isso.

Em algumas falas percebe-se a dificuldade do Serviço de Saúde do Salobrinho:

ENTREVISTADO 4: É,às vezes dificulta que, aqui no Salobrinho mesmo dificulta, às vezes não tem médico. Eles também não atende a gente bem, também. Aí manda logo para Ilhéus. Aí a fonte limpa é ir logo para Ilhéus. Às vezes a gente vai logo direto pra Ilhéus. 
O horário de serviço foi lembrado como um impedimento para todos aqueles que trabalhavam:

ENTREVISTADO 9: Ah, sim. Você foi direto no assunto. O meu trabalho me segura um pouco, entendeu? Assunto. O meu trabalho me segura um pouco, entendeu? [risos]. É isso aí, mas sempre o pessoal já sabe dos meus limites aí respeita meus pedidos. Vou ao médico: Vai, vai, vai. Sem problema. Entendeu?

Nas entrevistas ficou nítido que é tímida a presença do público masculino nos espaços de cuidado à saúde, principalmente quando comparada com a demanda dos usuários do sexo feminino, seja por questões culturais advindas da construção de modelos tradicionais de masculinidade, ou oriundas da estrutura organizacional dos serviços de saúde.

\section{CONSIDERAÇÕES FINAIS}

Por meio deste estudo ficou evidente a necessidade de implementar a política de saúde do homem, de investir em educação permanente dos profissionais de saúde para capacitá-los a atender às demandas da população masculina. Assim como entender o imaginário do homem, sua visão sobre o processo saúde doença, a forma como ele se relaciona com os serviços e sua percepção de vida saudável. Além disso, torna-se imperativo organizar os serviços conforme as características do referido grupo.

Os resultados demonstram que o grupo de homens atendido pela Unidade de Saúde da Família II é mais heterogêneo do que parecia, a princípio. A idade e a atividade laborativa dos entrevistados são os principais determinantes para o tipo de resposta obtida. Os dados também evidenciam que a maioria dos homens aposentados são moradores solitários ou com assistência reduzida de familiares. Ainda apontam que a saúde é cada vez mais importante na rotina dos homens à medida que eles envelhecem, o que justifica a adesão de homens mais velhos e a pequena presença de indivíduos jovens no serviço de saúde do Salobrinho.

Diante disto, é preciso promover ações de capacitação voltadas para os trabalhadores da saúde como forma de difundir a Política Nacional de Atenção Integral à Saúde do Homem, garantindo a assistência ao referido grupo populacional. Por fim, as medidas implantadas nos serviços precisam ser completadas com outras políticas públicas que permitam investimento de recursos e programas específicos para o homem 
e ajustados às realidades locais. 


\section{REFERÊNCIAS}

BRASIL, Ministério da Saúde. Portaria n 1944 de 27 de agosto de 2009.

BURILLE, Andréia; GERHARDT, Tatiana Engel. Conexões entre homens e saúde: discutindo algumas arranhaduras da masculinidade. AtheneaDigital, v. 13, n.2, p. 259266, jul. 2013.

CÂMARA, A.M.C.S; MELO, V.L.C.; GOMES, M.G. P.; PENA, B.C.; SILVA, A.P.; OLIVEIRA, K. M. de; MORAES, A.P.S; COELHO, G.R.; VICTORINO, L. R. Percepção do processo saúde-doença:Significados e valores da educação em saúde. Revista Brasileira de Educação Médica, v. 36, n. 1, Supl. 1, p. 40-50, 2012.

CHAKORA, E.S. Política Nacional de Atenção Integral à Saúde do Homem. Esc. Anna Nery, v. 18, n. 4, p.559-561, 2014. Disponível em: http://www.scielo.br/pdf/ean/v18n4/1414-8145-ean-18-04-0559.pdf. Acesso em:11 jan 2018.

GARUZI M, ACHITTI MCO, SATO CA, ROCHA SA, SPAGNUOLO RS. AcolhimentonaEstratégiaSaúde da Família: revisãointegrativa. RevistaPanamSalud Publica. 2014;35(2):144-9. Disponívelem:

<http://200.145.6.238/bitstream/handle/11449/111489/S10249892014000200009.pdf?se quence $=1 \&$ isAllowed=y $>$ Acessoem: 11 jan 2018 .

GOMIDE, M.F.S; PINTO, I.C; FIGUEIREDO, L.A. Acessibilidade e demandaemumaUnidade de Pronto Atendimento: perspectiva do usuário. Acta Paul Enferm., v.25, (Número Especial 2), p.19-25, 2012

GONÇALVES, H.A. Manual de Metodologia da Pesquisa Científica. 2.ed. São Paulo: Avercamp, 2014. 168p.

HARDMAN, M. N.; SOBRAL, H. C. T.; SILVA, A.M.L.; SOUZA, G.B.S.S.; FREITAS, M.M.; SILVA, B.T.O. Promoção e prevenção de saúde do homem. Interfaces Científicas - Saúde e Ambiente, Aracaju, v.2, p. 95-10, out. 2013. Disponível em: <www.periodicos.set.edu.br>. Acesso: out 2017.

LEAVEL H,Clark EG. MedicinaPreventiva. São Paulo, McGraw-Hill, 1976. IN: ROUQUAYROL, Maria Zélia. ALMEIDA FILHO, Naomar. Epidemiologia e Saúde. 7.ed. São Paulo: Medsi, 2013.

LEVORATO, C.C.; MELLO, L.M.; SILVA, A.S.; NUNES, A.A. Fatores associados àprocura por serviços de saúde numa perspectiva relacional de gênero. Ciência \& Saúde Coletiva, v. 19, n. 4, p.1263-1274, 2014. Disponível em: http://www.redalyc.org/html/630/63030543027/. Acesso em:14 jan 2018.

MOURA, E.C.; SANTOS, W.; NEVES, A.C.M.; GOMES, R.; SCHWARZ, E. Atenção à saúde dos homens no âmbito da EstratégiaSaúde da Família. Ciência \& Saúde Coletiva, v. 19, n. 2, p.429-438, 2014. Disponível em:< http:// www.scielo.br/pdf/csc/v19n2/1413-8123-csc-19-02-00429.pdf. Acesso em:11 jan. 
2018.

NEVES, A.C.S; KHOURY, H.T.T. Percepção de controle e qualidade de vida: comparação entre idosos institucionalizados e não institucionalizados. Revista

Brasileira de Geriatria Gerontologia, Rio de Janeiro, v. 17, n. 3, p.553-565, 2014.

PASCHOAL, S. M. P. Qualidade de vida na velhice. In: FREITAS, E.V. Tratado de geriatria e gerontologia. Rio de Janeiro: Guanabara Koogan, 2006.

SAMPAIO, C.A; CARVALHO, M.F; BRITO, L.C, GONÇALVES, D.V.C. Percepção sobre o adoecimento entre estudantes de cursos da área da saúde. Revista Brasileira de Educação Médica, v. 39, n. 1, p. 102-111, 2015.

ROUQUAYROL, M.Z. ALMEIDA FILHO, N. Epidemiologia e saúde. 7. ed. São Paulo: Medsi, 2013.

RIBEIRO, C.R.; GOMES, R.; MOREIRA, M.C.N. Encontros e desencontros entre a saúde do homem, a promoção da paternidade participativa e a saúde sexual e reprodutiva na atenção básica. Physis Revista de Saúde Coletiva, Rio de Janeiro, v. 27, n. [1], p.41-60, 2017. Disponível em:http://www.redalyc.org/html/4008/400851663005/. Acesso em: 16 jan 2018.

SONTAG, S. A doença como metáfora. Rio de Janeiro: Edições Graal, 1984. (Coleção Tendências; 6). 